\title{
The Glutathione-S-Transferase Mu 1 null genotype modulates ozone-induced airway inflammation in humans
}

\author{
Neil E. Alexis, $\mathrm{PhD}^{1,3}$, Haibo Zhou, $\mathrm{PhD}^{1,4}$, John $\mathbf{C}$ Lay, $\mathrm{PhD}^{1,3}$, Bradford Harris, $\mathbf{M D}^{1,3}$, \\ Michelle L Hernandez, MD ${ }^{1,3}$, Tsui-Shan Lu, PhD ${ }^{1,4}$, Philip A. Bromberg, MD ${ }^{1,2}$, David \\ Diaz-Sanchez, $\mathrm{PhD}^{5}$, Robert B. Devlin, $\mathrm{PhD}^{5}$, Steven R. Kleeberger, $\mathrm{PhD}^{6}$, and David B. \\ Peden, MD ${ }^{1,2,3}$ \\ ${ }^{1}$ Center for Environmental Medicine, Asthma and Lung Biology, UNC School of Medicine, Gillings \\ School of Global Public Health, Chapel Hill, NC \\ ${ }^{2}$ Department of Medicine, UNC School of Medicine, Gillings School of Global Public Health, \\ Chapel Hill, NC \\ ${ }^{3}$ Department of Pediatrics, UNC School of Medicine, Gillings School of Global Public Health, \\ Chapel Hill, NC \\ ${ }^{4}$ Department of Biostatistics, Gillings School of Global Public Health, Chapel Hill, NC \\ ${ }^{5}$ Environmental Public Health Division, National Health and Environmental Effects Research \\ Laboratory, US EPA, Research Triangle Park, NC \\ ${ }^{6}$ Laboratory of Respiratory Biology, National Institute of Environmental Health Sciences, \\ Research Triangle Park, NC
}

\section{Abstract}

\begin{abstract}
Background-The Glutathione-S-Transferase Mu 1 null genotype has been reported to be a risk factor for acute respiratory disease associated with increases in ambient air ozone. Ozone is known to cause an immediate decrease in lung function and increased airway inflammation. However, it is not known if GSTM1 modulates these ozone responses in vivo in humans
\end{abstract}

Objective-The purpose of this study was to determine if the GSTM1 null genotype modulates ozone responses in humans.

\begin{abstract}
Methods-Thirty-five normal volunteers were genotyped for the GSTMI null mutation and underwent a standard ozone exposure protocol to determine if lung function and inflammatory responses to ozone were different between the 19 GSTM1 normal and 16 GSTM1 null volunteers.

Results-GSTM1 did not modulate lung function responses to acute ozone. Granulocyte influx 4 hours after challenge was similar between GSTM1 normal and null volunteers. However, GSTM1 null volunteers had significantly increased airway neutrophils 24 hours after challenge, as well as increased expression of HLA-DR on airway macrophages and dendritic cells.
\end{abstract}

(C) 2009 American Academy of Allergy, Asthma and Immunology. Published by Mosby, Inc. All rights reserved.

Corresponding Author: David B. Peden, MD, Center for Environmental Medicine, Asthma, and Lung Biology, 104 Mason Farm Road, CB\#7310, The University of North Carolina School of Medicine, Chapel Hill, NC 27599-7310, 919-966-0768 (phone), 919-966-9863 (fax) peden@med.unc.edu.

Publisher's Disclaimer: This is a PDF file of an unedited manuscript that has been accepted for publication. As a service to our customers we are providing this early version of the manuscript. The manuscript will undergo copyediting, typesetting, and review of the resulting proof before it is published in its final citable form. Please note that during the production process errors may be discovered which could affect the content, and all legal disclaimers that apply to the journal pertain. 
Conclusion-The GSTM1 null genotype is associated with increased airways inflammation 24 hours following ozone exposure, consistent with the lag time observed between increased ambient air ozone exposure and exacerbations of lung disease.

Clinical Implications-These observations suggest that the GSTM1 null genotype likely confers increased risk for exacerbation of ozone-induced lung disease through promoting an enhanced neutrophilic and monocytic inflammatory response to ozone.

Capsule summary-The GSTM1 null genotype is associated with increased risk for ozoneinduced lung disease. We report the GSTMI genotype modulates ozone-induced inflammation but not lung function, and may predict persons at risk for environmental lung disease.

\section{Keywords}

Glutathione-S-Transferase Mu 1; Ozone; Pollution; Inflammation; Polymorphonuclear Neutrophil; Macrophage; Dendritic cell

\section{Introduction}

A number of pro-oxidant air pollutants, including particulate matter, tobacco smoke, diesel exhaust and ozone $\left(\mathrm{O}_{3}\right)$ have been linked to exacerbation of asthma and lung disease(1-5).

Glutathione-S-Transferase Mu 1 (GSTM1) is a Phase II antioxidant enzyme regulated by the transcription factor NF-E2-related factor-2 (NRF2)(6). The GSTM1 null (GSTM1-) genotype results in a failure to produce the GSTM1 protein. As noted in many reviews, the GSTM1- genotype confers increased risk for adverse health effects due to exposure to these air pollutants(1-5). As reviewed by Giesler and Olshan(7), case-control studies conducted in the United States of various tumors report frequencies of the GSTM1- genotype that range from 23 to 41 percent in African Americans, 32 to 53 percent in Asian Americans, 40 to 53 percent in Hispanic Americans, and 35 to 62 percent in European Americans. Furthermore, prevalence of the GSTMI- genotype ranges from 48 to 57 percent in European Americans as reported in several population studies. Thus, this gene variant occurs in high frequency in most ethnic populations.

Many investigators have reported increased susceptibility to lung disease following exposure to environmental tobacco smoke associated with the GSTM1- genotype. One study of children exposed to environmental tobacco smoke found that those children who were either GSTM1- or homozygous for the GSTP1Val105 allele had increased risk of asthma at younger ages, with an increased risk for decreased lung function in adolescence. (8) Others have reported that children with the GSTM1- genotype are significantly more likely to have increased risk of asthma or acute respiratory illnesses if they are born to mothers who smoke during pregnancy (9) or if they had been exposed to environmental tobacco smoke(10). Human challenge studies have been conducted to investigate the role of the GSTMI- genotype on the interaction of second-hand tobacco smoke exposure with diesel exhaust exposure on response to allergen in allergic volunteers. In these studies, GSTM1- volunteers have increased allergen-induced histamine release and IgE production in the nasal airway following exposure to these pollutants(11;12).

A series of reports of a cohort of children with asthma in Mexico City have demonstrated an effect of ambient air $\mathrm{O}_{3}$ exposure on asthma exacerbation. This group reported that asthmatic children with the GSTM1- genotype have increased risk for $\mathrm{O}_{3}$-induced asthma exacerbation, and are more likely to benefit from antioxidant supplementation to prevent such exacerbations. They have also reported that the Pro/Pro homozygous genotype (vs. Pro/ Ser or Ser/Ser genotypes) at the 187 position for the NAD(P)H:quinone oxidoreductase (NQO1), increases risk for asthma in GSTM1-children(13-16). Another study examined the 
effect of $\mathrm{O}_{3}$ levels of $>0.08$ ppm on 24 bicyclists while undertaking a 2 hour ride on lung function and serum levels of CC16 (Clara Cell Protein 16) which is a marker for increased respiratory cell permeability (17). Eight of these 24 persons had both the wild type NQOI genotype and the GSTM1-genotype and were found to have a strong correlation between both serum CC16 and decreased lung function and ambient air $\mathrm{O}_{3}$ levels $>0.08 \mathrm{ppm}$. Taken together, these observations indicate that the GSTM1-genotype is an important determinant of susceptibility to $\mathrm{O}_{3}$-induced lung disease.

Human challenge studies of both asthmatic and non-asthmatic adults revealed three distinct responses following $\mathrm{O}_{3}$ challenge: an immediate decrease in lung function which is most likely mediated by neural reflexes; increased bronchial reactivity; and increases in airway inflammation typified by increased influx of polymorphonuclear neutrophils (PMNs) (18). The effect of $\mathrm{O}_{3}$ challenge on macrophage and monocyte populations is still being defined.

Acute $\mathrm{O}_{3}$ challenge has been reported to decrease macrophage numbers in the airway $(18 ; 19)$, while others have found that repeated exposure to $\mathrm{O}_{3}$ augments airway macrophage populations(20). Additionally, we have reported that exposure to $\mathrm{O}_{3}$ causes increased expression of a number of innate and acquired immune surface proteins on airway monocytes and macrophages, including CD11b, CD14, CD16, CD86 and HLA-DR, that occur in concert with increases in airway PMNs(19). We hypothesized that an important mechanism by which $\mathrm{O}_{3}$ exerts adverse respiratory effects in humans involves recruitment of activated innate immune cells to the airway with enhanced expression of cell surface proteins like CD14, CD86 and HLA-DR. These cells would likely enhance response to allergen in allergic persons as well as responses to particulates containing biological components such as endotoxin which may have health effects in allergic and non-allergic populations.

To test this hypothesis, healthy volunteers who had the GSTM1+ or GSTM1- genotype underwent inhalation challenge to $0.4 \mathrm{ppm} \mathrm{O}_{3}$ for two hours. Changes in lung function, PMN and macrophage numbers, expression of cell surface markers on immune cells, macrophage function and cytokine levels were examined. If the GSTM1-genotype is associated with decreased lung function or increased airway neutrophil and macrophage responses to $\mathrm{O}_{3}$, then this would be an important risk factor for acute disease morbidity associated with $\mathrm{O}_{3}$.

\section{METHODS}

\section{Volunteer Recruitment and Inclusion Criteria}

This protocol was reviewed and approved by the University of North Carolina Committee on the Rights of Human Subjects (Institutional Review Board). All subjects underwent a physical examination, a routine blood panel with $\mathrm{CBC}$ and differential, allergy skin testing, and genotyping for the GSTMI- or GSTMI+ genotype using previously reported techniques(21). Subjects were required to have a negative methacholine challenge. Female subjects had to have a negative urine pregnancy test prior to challenge and all volunteers were required to be free of chronic cardiovascular or respiratory illness, and be free of acute respiratory illness within 4 weeks of $\mathrm{O}_{3}$ challenge. All subjects had $\mathrm{FEV}_{1}$ and $\mathrm{FVC} \geq 80 \%$ predicted and $\mathrm{FEV}_{1} / \mathrm{FVC} \geq 75 \%$ predicted normal for height and age, and were nonsmokers with no smoking history. All subjects were screened for their ability to provide an adequate induced-sputum sample during their training session. Further recruitment criteria are detailed in the online supplement, 


\section{Ozone Exposure and testing protocol}

Ozone Exposures-The $\mathrm{O}_{3}$ exposures were conducted in an $\mathrm{O}_{3}$ exposure chamber at the US-EPA Human Studies Facility on the campus of the University of North Carolina, Chapel Hill, NC. Each subject was exposed to $\mathrm{O}_{3}(0.4 \mathrm{ppm})$ for 2 hours while performing four 15 minute sessions of intermittent moderate exercise (minute ventilation or $\mathrm{VE}_{\min }=30-40 \mathrm{~L} /$ min) on a treadmill, separated by 15 minutes of seated rest. Lung function, breath sounds, and vital signs were assessed before and after exposure.

Sputum was obtained 4 and 24 hour post exposure and processed as previously described. $(22 ; 23)$ This is further outlined in the online supplement. Sputum was assessed for total and differential cell counts, immunophenotyping of neutrophils, macrophages, monocytes, and dendritic cells, (19;24) and functional assays for oxidative burst activity and phagocytosis of opsonized zymosan were assessed by flow cytometry on sputum macrophages(22;25). Sputum supernatants were also assessed for cytokine concentration, as described in the online supplement. Lung function and genotyping procedures are also described in the online supplement.

\section{Statistical Analysis}

Our a priori primary hypotheses were that persons with the GSTM1-genotype would have increased effects of $\mathrm{O}_{3}$ on lung function (greater decrements in lung function) and airway inflammation (increases in airway neutrophils and decreases in airway macrophages). The effect of $\mathrm{O}_{3}$ on airway cell immunophenotypes and macrophage function were also determined to test the exploratory hypotheses that persons with the GSTMI- genotype would have enhanced airway macrophage activation and cell function.

Paired t-tests were used to compare each effects of $\mathrm{O}_{3}$ lung function immediately and 24 hours after challenge and sputum endpoints at 4 and 24 hours post challenge to baseline measures within each genotype cohort (GSTMI- and GSTM1+) to first determine the effect of $\mathrm{O}_{3}$ on these endpoints. To test the primary hypothesis that persons with the GSTMIgenotype have enhanced responses to $\mathrm{O}_{3}$, we compared the change from baseline at 4 or 24 hours for a given endpoint after $\mathrm{O}_{3}$ challenge between the GSTM1- and GSTM1+ groups using the two sample t-test. Spirometric data immediately and 24 hours after challenge were normalized and expressed as \% change from baseline. Other endpoints were transformed using natural logarithm transformation to achieve a normal distribution prior to T-test analysis. For primary hypotheses, significance was set at $\alpha=0.05$. For exploratory hypotheses, nominal $\mathrm{p}$ values $<0.10$ are reported.

Although the ability to produce adequate sputum was an entrance criterion, some sputum samples recovered at baseline or after challenge did not yield a sufficient numbers of cells for recovery of all endpoints. This occurred randomly across the baseline, 4-hour post and 24-hours post exposure sputum collections. To account for the missing data points and maximize statistical power for hypothesis testing, we employed multiple imputation methods (26). Data imputation was not performed on any endpoint where a subject had missing data at all timepoints due to inadequate sputum cell recovery. For all primary endpoints, the sample size is $\mathrm{n}=19$ for $G S T M 1+$ and $\mathrm{n}=16$ for $G S T M 1-$ volunteers. For exploratory endpoints, the assessed sample size is noted in the results section. Thirty imputations were performed for each set of sputum endpoints (e.g. baseline PMN/mg sputum values in GSTM1+ volunteers) which contained missing data. Only mean and standard error values from actual data are depicted and reported in the results section, with imputed data used only for hypothesis testing. A detailed description of the imputation methodology appears in the on line supplement. 


\section{Results \\ Demographics}

Demographic data for the thirty-five healthy volunteers, ranging in age from 18-35 years, recruited for challenge to $0.4 \mathrm{ppm} \mathrm{O}_{3}$ are presented in Table 1. Twelve of the 35 (32.3\%) were atopic as determined by skin testing, though all were non-asthmatic as determined by methacholine challenge. The GSTMI genotype cohorts are described in Table 1.

\section{Effect of $0.4 \mathrm{ppm}$ ozone on lung function}

The effect of $\mathrm{O}_{3}$ on lung function was a primary endpoint for this study. Figure 1 shows that $\mathrm{O}_{3}$ exposure caused significantly ( $\mathrm{p}<0.05$ ) decreased FEV1 (top) and FVC (bottom) immediately after challenge in GSTMI+ $(\mathrm{N}=19)$ and GSTMI- $(\mathrm{N}=16)$ subjects and are expressed as \% of baseline value. No significant differences in lung function responses to $\mathrm{O}_{3}$ were found between the GSTMI+ and GSTM1- cohorts, with both cohorts having significant and similar decreases in FEV1 and FVC at immediately and 24 hours post exposure.

\section{Effect of 0.4 ppm ozone on airway PMNs and macrophages}

The effect of $\mathrm{O}_{3}$ on airway PMNs and macrophages was also a primary endpoint for this study. Figure 2 (top) shows that the GSTM1- cohort $(\mathrm{n}=16)$ had significantly increased sputum PMNs 4 (*p=0.021), and 24 hours $(* \mathrm{p}=0.001)$ after challenge. The GSTM1+ cohort had significantly increased sputum PMNs 4 hours after challenge $(* \mathrm{p}=0.01)$ with a relative decrease in PMNs at 24 hours such that they were not significantly increased compared to baseline. A comparison of the changes from baseline to 24 hours after challenge in the GSTMI+ and GSTM1 - cohorts demonstrated that the GSTM1- cohort had a significantly increased PMN influx 24 hours after challenge $\left({ }^{+} \mathrm{p}=0.03\right)$.

The bottom panel in Figure 2 shows that macrophage counts were significantly decreased from baseline values $4\left({ }^{*} \mathrm{p}=0.013\right)$ and 24 hours $(* \mathrm{p}=0.001)$ after $\mathrm{O}_{3}$ exposure in the GSTM1+ group. In the GSTM1- group, a small, non-significant decrease in macrophage numbers was found at 4 hours after challenge compared to baseline, with the mean value increasing to a level above that seen at baseline at 24 hours. A comparison of the 24 hour macrophage response in the GSTM1+ and GSTM1- cohorts demonstrated that the GSTM1cohort had a significantly increased macrophage count 24 hours after challenge $\left({ }^{+} \mathrm{p}=0.002\right)$. For macrophages and neutrophils, data was recovered 17 of 19 GSTMI+ volunteers at baseline, all volunteers 4 hours post challenge, and 17 of 1924 hours after challenge. For GSTM1- volunteers, data was recovered from 15 of 16 volunteers at baseline and 4 hours, and 13 of 16 volunteers 24 hours post challenge. Multiple imputation techniques were used to estimate missing values for each data set as described in the Methods section.

\section{Effect of $0.4 \mathrm{ppm}$ ozone on airway macrophage and dendritic cell function}

Two measures of macrophage function, were assessed as exploratory endpoints: oxidative burst activity following activation with zymosan particles (Figure 3, top panel) and uptake of opsonized zymosan particles, phagocytosis (Figure 3, middle panel). Oxidative burst was increased in airway macrophages recovered from GSTM1- volunteers $(\mathrm{n}=16) 24$ hours after $\mathrm{O}_{3}$ challenge when compared to macrophages from 17 GSTM1+ volunteers $\left({ }^{+} \mathrm{p}=0.03\right)$.

Macrophage phagocytosis was increased 24 hours after $\mathrm{O}_{3}$ challenge in $G S T M 1-(\mathrm{n}=15)$ vs. GSTMI+ $(\mathrm{n}=19)$ volunteers $\left({ }^{+} \mathrm{p}=0.05\right)$.

Another exploratory endpoint we examined was the effect of $\mathrm{O}_{3}$ on cell surface phenotypes on monocyte and macrophage populations as defined using flow cytomtery. We focused on the effect of $\mathrm{O}_{3}$ on expression of CD11b, CD14, CD16, CD64, CD86 and HLA-DR in 
monocytes, immature macrophages, mature macrophages, PMNs and dendritic cells. We have previously reported that $\mathrm{O}_{3}$ exposure enhances expression of these markers on airway monocytes after $\mathrm{O}_{3}$ challenge, and confirmed this observation in the present study with the exception of CD16 (data not shown). When we analyzed the effect of $\mathrm{O}_{3}$ on surface marker expression in the GSTMI+ (N=9) and GSTM1- $(\mathrm{N}=11)$ groups (Figure 3, bottom panel), we found three significant differences at 24 hours for GSTM1-individuals: 1) increased expression of CD14 on airway PMNs (Figure E1, online supplement); 2) increased expression of HLA-DR on airway dendritic cells at 24 hours post exposure $(* \mathrm{p}=0.003)$ and 3 ) increased HLA-DR expression on macrophages $(* \mathrm{p}=0.03) 24$ hours post exposure. The 24 hour HLA-DR response was significantly different between GSTMI+ and GSTM1volunteers for dendritic cells $\left({ }^{+} \mathrm{p}=0.02\right)$ and macrophages $\left({ }^{+} \mathrm{p}=0.03\right)$.

\section{Airway Cytokines}

We also examined sputum supernatants for a number of pro-inflammatory cytokines (gamma interferon, IL-1 $\beta$, IL-2, IL-4, IL-5, IL-8, IL-10, IL-12p70, IL-13, MIP1 $\alpha$ and $\mathrm{TNF} \alpha)$. Of these, we observed significant increases in IL-1 $\beta$ at $4(\mathrm{p}=0.01)$ and 24 hours ( $\mathrm{p}=0.05$ ) post $\mathrm{O}_{3}$ and IL-8 24 hours post $\mathrm{O}_{3}$ in the GSTM1- cohort, while the GSTMI+ also showed elevated levels but these were not statistically significant. No difference between genotypes was observed. These results are further described in the online supplement

\section{DISCUSSION}

In this study, we tested the hypothesis that the GSTM1- genotype would increase sensitivity to inhaled challenge to $0.4 \mathrm{ppm} \mathrm{O}_{3}$, with the primary endpoints being change in lung function (FEV1 and FVC) and influx of neutrophils to the airway four and 24 hours after acute challenge. We found decreased mean FEV1 and $\mathrm{FVC}$ after $\mathrm{O}_{3}$ challenge in GSTMI+ and GSTMI- volunteers had with no difference in lung function response between these groups. We likewise found no difference in airway neutrophils 4 hours after challenge between the genotype groups, with both groups demonstrating increased airway neutrophils. However, at 24 hours post $\mathrm{O}_{3}$ challenge, we found a very notable and significant increase in airway neutrophils in the GSTMI- cohort that was not found in the GSTMI+ group.

We also found that there was a significant decrease in the macrophages/mg sputum recovered in the GSTM1+ volunteers at 4 and 24 hours that was not observed in the GSTM1- group. Macrophage-mediated clearance of apoptotic luminal cells would depend on the presence of apoptotic PMNs in the airways, hence PMN resolution resulting in fewer PMNs at 24h in the GSTM1+ cohort may explain fewer macrophages at that time point. Persistent inflammation however, as observed in the GSTM1- cohort at 24 hours may render the need for increased macrophages and enhanced macrophage-mediated clearance. Thus, comparing the differences in the change from baseline values between the groups at 24 hours after challenge, the GSTM1- volunteers had a significantly greater number of macrophages present in the airway. When compared to baseline values, oxidative burst and phagocytic capability of airway macrophages recovered 24 hours after $\mathrm{O}_{3}$ challenge were increased in the GSTM1- vs the GSTM1+ volunteers. We also observed increased HLA-DR expression on macrophages and dendritic cells recovered from GSTM1- volunteers 24 hours after challenge. We have previously reported that concurrent with $\mathrm{O}_{3}$-induced cell changes in the airway, namely neutrophil and monocytic cell influx, there are increases in expression of innate and acquired immune cell surface proteins on airway macrophages and monocytes. These include CD11b, CD14, CD86 and HLA-DR (19). The persistence of macrophages in the airways of GSTM1- volunteers 24 hours after challenge is therefore likely biologically significant because these cell surface proteins are central in mediating innate and acquired immune responses that can mediate exacerbations of lung disease. 
Adverse events associated with increases in ambient air $\mathrm{O}_{3}$ exposure generally occur 24 to 48 hours after the $\mathrm{O}_{3}$ event has occurred as reviewed by Peden et al (18). As described in the Introduction, the GSTM1- genotype is associated with increased risk for such adverse events. If these effects were primarily due to an immediate effect of $\mathrm{O}_{3}$ on lung function, air pollution events should result in immediate (same day) exacerbation of disease. Our observations that GSTM1- volunteers have increased neutrophilic inflammation in the airway, increased presence of functionally activated macrophages, and increased expression of HLA-DR on airway macrophages and dendritic cells 24 hours after $\mathrm{O}_{3}$ challenge suggest that these inflammatory and innate immune changes likely account for these effects. These changes could directly modify the airway, or perhaps in the case of allergic asthmatics, enhance response to inhaled allergen, which has been reported by many investigators, as noted previously(18).

It is unclear whether the increases in neutrophils and macrophages in the airways 24 hours after $\mathrm{O}_{3}$ challenge in GSTM1- volunteers reflects a primary difference in these cells, or increased chemo-attraction and activation of inflammatory and immune cells by mediators secreted by structural tissues of the airway following exposure to $\mathrm{O}_{3}$. There is ample evidence that $\mathrm{O}_{3}$ stimulates airway epithelial cells in ways which may influence inflammation. Ozone up-regulates cytokine and eicosanoid secretion by epithelial cells, as noted previously $(27 ; 28)$ and reported here in the GSTM1- cohort, as they demonstrated significantly elevated levels of the pro-inflammatory cytokines IL $1-\beta$ and IL-8 following $\mathrm{O}_{3}$, the latter a potent chemoattractant for PMN influx. Epithelial cells stressed with $\mathrm{O}_{3}$ also release ATP, which is a pro-inflammatory signal for a number of inflammatory cells(29). Ozone actions on epithelial lining fluid may also result in production of lipid peroxidation products that have pro-inflammatory actions $(27 ; 28 ; 30 ; 31)$.

There are suggestions that the airway epithelium of GSTM1- individuals has increased susceptibility to $\mathrm{O}_{3}$. A study of the effect of in vitro $\mathrm{O}_{3}$ exposure on nasal mucosal explants obtained from GSTM1+ and GSTM1- volunteers reveals that tissues from GSTM1volunteers have significantly increased superoxide dismutase activity relative to GSTMI+ tissues(32). In the study by Bergamaschi et al examining the effect of ambient $\mathrm{O}_{3}$ on bicyclists, the GSTM1- genotype was a component of the haplotype associated with a correlation between $\mathrm{O}_{3}$ and Clara Cell Protein 16 (CC16), a marker of epithelial cell injury(17). Taken together, these observations suggest that airway epithelial cells from GSTM1- persons have increased susceptibility to $\mathrm{O}_{3}$. We hypothesize that GSTM1 genotype-mediated differences in epithelial cell secretion of pro-inflammatory cytokine response to $\mathrm{O}_{3}$ may account at least in part, for the effect of the GSTM1- genotype on $\mathrm{O}_{3}$ induced airway inflammation.

It is important to note limitations to the current study. We did not assess changes in airway hyperresponsiveness, and we acknowledge that such changes could also account for increased risk for exacerbation of $\mathrm{O}_{3}$-induced disease associated with the GSTM1genotype. Also, in contrast to our study, Bergamaschi et al found that bicyclists exposed to lower levels of ambient $\mathrm{O}_{3}(0.08 \mathrm{ppm})$ had a significant effect on lung function in those with the $N Q O 1$ wild type/GSTM1- haplotype (17). It is possible that the level of $\mathrm{O}_{3}$ we employed in this study may have been so high that a GSTM1 genotype modulation of lung function response may have been masked.

Additionally, 16 of 16 of our GSTM1- volunteers were Caucasian, whereas 8 of the 19 GSTM1+ volunteers were African American, 1 was Asian and 10 were Caucasian. The sample size of this study limits the ability to adjust for ethnicity, and it is possible that the differences we observed between the GSTMI+ and GSTM1- populations in this study may be due to other genetic factors which stratify by race, rather than GSTM genotype. If factors 
other than differences in the GSTM genotype accounted for the differential responses to ozone we observed, then mechanisms other than impaired antioxidant capability would need to be explored as potential risk factors for pollutant-induced lung inflammation. However, as noted in the Introduction, the prevalence of the GSTM1- genotype is high across most studied ethnic groups. As future studies enhance our sample size, we will need to confirm that the effect of the GSTMI- genotype on $\mathrm{O}_{3}$ induced inflammation is true across multiple ethnic groups, which would make it less likely that other factors account for the differences we report herein.

In summary, we report that volunteers with the GSTM1- genotype have no differential lung function response to $0.4 \mathrm{ppm} \mathrm{O}_{3}$ compared to the GSTM1+ group, but do have a notable increase in airway PMNs and activated macrophages at 24 hours post $\mathrm{O}_{3}$ challenge compared to GSTM1+ volunteers. The GSTM1- genotype has been associated with increased risk for exacerbations of airway disease and asthma due to pollutant exposure. Our observations on inflammatory response to $\mathrm{O}_{3}$ in GSTM1- volunteers temporally matches the epidemiological observations that show ambient $\mathrm{O}_{3}$-associated adverse effects 24 hours after exposure. Taken together, these observations are consistent with the hypotheses that GSTM1 is an important risk factor for $\mathrm{O}_{3}$-induced exacerbations of respiratory disease due in part to GSTM1-associated differences in inflammatory response to $\mathrm{O}_{3}$.

\section{Supplementary Material}

Refer to Web version on PubMed Central for supplementary material.

\section{Acknowledgments}

The authors gratefully acknowledge the skillful assistance of Martha Almond, Aline Kala, Margaret Herbst, Carole Robinette, Heather Wells, Nathaniel Bailey, Fernando Dimeo, Danuta Sujkowski, Evan Trudeau, and Nolan Sweeny from the UNC Center for Environmental Medicine, Asthma and Lung Biology, Maryann Bassett, Tracy Montilla and Deborah Levin of the Environmental Public Health Division of the US EPA and Wes Gladwell of the Laboratory of Respiratory Biology of the NIEHS in the completion of this project.

Funding Sources: NIH Grants R01ES012706, P01AT002620, US EPA Cooperative Agreement CR 83346301, NIEHS Division of Intramural Research. Although the research described in this article has been funded wholly or in part by the United States Environmental Protection Agency through cooperative agreement CR-83346301 with the Center for Environmental Medicine and Lung Biology at the University of North Carolina at Chapel Hill, it has not been subjected to the Agency's required peer and policy review, and therefore does not necessarily reflect the views of the Agency and no official endorsement should be inferred

\section{Abbreviations}

GSTM1 Glutathione-S-Transferase Mu 1

$\mathrm{O}_{3}$

NQO1

NRF2

PMN

FVC

FEV1

CC16

DC

MFI
Ozone

NAD(P)H:quinone oxidoreductase

Nuclear Factor-E2-related factor-2

Polymorphonuclear Neutrophil

Forced Vital Capacity

Forced expiratory Volume at one second

Clara Cell Protein 16

Dendritic Cell

mean fluorescence intensity 


$\begin{array}{ll}\text { VEmin } & \text { Expiratory minute ventilation } \\ \text { DTT } & \text { dithiothreitol } \\ \text { DC } & \text { dendritic cell } \\ \text { MFI } & \text { Mean Fluorescence Intensity }\end{array}$

\section{References}

1. London SJ. Gene-air pollution interactions in asthma. Proc Am Thorac Soc 2007;4(3):217-220. [PubMed: 17607002]

2. Peden DB. The epidemiology and genetics of asthma risk associated with air pollution. J Allergy Clin Immunol 2005;115(2):213-219. [PubMed: 15696070]

3. Riedl M, Diaz-Sanchez D. Biology of diesel exhaust effects on respiratory function. J Allergy Clin Immunol 2005;115(2):221-228. [PubMed: 15696072]

4. Schwartz J. Air pollution and children's health. Pediatrics 2004;113(4 Suppl):1037-1043. [PubMed: 15060197]

5. Trasande L, Thurston GD. The role of air pollution in asthma and other pediatric morbidities. J Allergy Clin Immunol 2005;115(4):689-699. [PubMed: 15805986]

6. Li N, Nel AE. Role of the Nrf2-mediated signaling pathway as a negative regulator of inflammation: implications for the impact of particulate pollutants on asthma. Antioxid Redox Signal 2006;8(1-2): 88-98. [PubMed: 16487041]

7. Geisler SA, Olshan AF. GSTM1, GSTT1, and the Risk of Squamous Cell Carcinoma of the Head and Neck: A Mini-HuGE Review. American Journal of Epidemiology 2001;154(2):95-105. [PubMed: 11447041]

8. Palmer CN, Doney AS, Lee SP, Murrie I, Ismail T, Macgregor DF, et al. Glutathione S-transferase M1 and P1 genotype, passive smoking, and peak expiratory flow in asthma. Pediatrics 2006;118(2): 710-716. [PubMed: 16882827]

9. Gilliland FD, Li YF, Dubeau L, Berhane K, Avol E, McConnell R, et al. Effects of glutathione Stransferase M1, maternal smoking during pregnancy, and environmental tobacco smoke on asthma and wheezing in children. Am J Respir Crit Care Med 2002;166(4):457-463. [PubMed: 12186820]

10. Kabesch M, Hoefler C, Carr D, Leupold W, Weiland SK, von Mutius E. Glutathione S transferase deficiency and passive smoking increase childhood asthma. Thorax 2004;59(7):569-573. [PubMed: 15223862]

11. Gilliland FD, Li YF, Gong H Jr, Diaz-Sanchez D. Glutathione s-transferases M1 and P1 prevent aggravation of allergic responses by secondhand smoke. Am J Respir Crit Care Med 2006;174(12):1335-1341. [PubMed: 17023730]

12. Gilliland FD, Li YF, Saxon A, Diaz-Sanchez D. Effect of glutathione-S-transferase M1 and P1 genotypes on xenobiotic enhancement of allergic responses: randomised, placebo-controlled crossover study. The Lancet 2004;363(9403):119-125.

13. David GL, Romieu I, Sienra-Monge JJ, Collins WJ, Ramirez-Aguilar M, Rio-Navarro BE, et al. NAD(P)H: Quinone Oxidoreductase and Glutathione S-Transferase M1 Polymorphisms and Childhood Asthma. Am J Respir Crit Care Med. 2003

14. Romieu I, Sienra-Monge JJ, Ramirez-Aguilar M, Tellez-Rojo MM, Moreno-Macias H, Reyes-Ruiz NI, et al. Antioxidant supplementation and lung functions among children with asthma exposed to high levels of air pollutants. Am J Respir Crit Care Med 2002;166(5):703-709. [PubMed: 12204869]

15. Romieu I, Sienra-Monge JJ, Ramirez-Aguilar M, Moreno-Macias H, Reyes-Ruiz NI, Estela del Rio-Navarro B, et al. Genetic polymorphism of GSTM1 and antioxidant supplementation influence lung function in relation to ozone exposure in asthmatic children in Mexico City. Thorax 2004;59(1):8-10. [PubMed: 14694237] 
16. Romieu I, Ramirez-Aguilar M, Sienra-Monge JJ, Moreno-Macias H, Rio-Navarro BE, David G, et al. GSTM1 and GSTP1 and respiratory health in asthmatic children exposed to ozone. Eur Respir J 2006;28(5):953-959. [PubMed: 16870661]

17. Bergamaschi E, De Palma G, Mozzoni P, Vanni S, Vettori MV, Broeckaert F, et al. Polymorphism of quinone-metabolizing enzymes and susceptibility to ozone-induced acute effects. Am J Respir Crit Care Med 2001;163(6):1426-1431. [PubMed: 11371413]

18. Peden, DB. MIDDLETON'S ALLERGY: PRINCIPLES AND PRACTICE. Air Pollution: Indoor and Outdoor. In: Adkinson, NF., Jr; Busse, W.; Bochner, B.; Holgate, S.; Simons, FE.; Lemanske, R., editors. Mosby. 2008. p. 495-508.

19. Lay JC, Alexis NE, Kleeberger SR, Roubey RA, Harris BD, Bromberg PA, et al. Ozone enhances markers of innate immunity and antigen presentation on airway monocytes in healthy individuals. J Allergy Clin Immunol. 2007

20. Arjomandi M, Witten A, Abbritti E, Reintjes K, Schmidlin I, Zhai W, et al. Repeated exposure to ozone increases alveolar macrophage recruitment into asthmatic airways. Am J Respir Crit Care Med 2005;172(4):427-432. [PubMed: 15937293]

21. Bell DA, Taylor JA, Paulson DF, Robertson CN, Mohler JL, Lucier GW. Genetic risk and carcinogen exposure: a common inherited defect of the carcinogen461 metabolism gene glutathione S-transferase M1 (GSTM1) that increases susceptibility to bladder cancer. J Natl Cancer Inst 1993;85(14):1159-1164. [PubMed: 8320745]

22. Alexis NE, Lay JC, Zeman K, Bennett WE, Peden DB, Soukup JM, et al. Biological material on inhaled coarse fraction particulate matter activates airway phagocytes in vivo in healthy volunteers. J Allergy Clin Immunol 2006;117(6):1396-1403. [PubMed: 16751003]

23. Alexis NE, Eldridge MW, Peden DB. Effect of inhaled endotoxin on airway and circulating inflammatory cell phagocytosis and CD11b expression in atopic asthmatic subjects. J Allergy Clin Immunol 2003;112(2):353-361. [PubMed: 12897742]

24. Lay JC, Alexis NE, Zeman KL, Peden DB, Bennett WD. In vivo uptake of inhaled particles by airway phagocytes is enhanced in patients with mild asthma compared with normal volunteers. Thorax 2009;64(4):313-320. [PubMed: 19052052]

25. Alexis N, Soukup J, Ghio A, Becker S. Sputum phagocytes from healthy individuals are functional and activated: a flow cytometric comparison with cells in bronchoalveolar lavage and peripheral blood. Clin Immunol 2000;97(1):21-32. [PubMed: 10998314]

26. Little, RJA.; Rubin, DB. Statistical analysis with missing data. New York: John Wiley \& Sons; 1987.

27. Kleeberger SR, Peden D. Gene-environment interactions in asthma and other respiratory diseases. Annual Review of Medicine 2005;56:383-400.

28. Ciencewicki J, Trivedi S, Kleeberger SR. Oxidants and the pathogenesis of lung diseases. J Allergy Clin Immunol 2008;122(3):456-468. [PubMed: 18774381]

29. Ahmad S, Ahmad A, McConville G, Schneider BK, Allen CB, Manzer R, et al. Lung epithelial cells release ATP during ozone exposure: signaling for cell survival. Free Radic Biol Med 2005;39(2):213-226. [PubMed: 15964513]

30. Leikauf GD, Zhao Q, Zhou S, Santrock J. Ozonolysis products of membrane fatty acids activate eicosanoid metabolism in human airway epithelial cells. Am J Respir Cell Mol Biol 1993;9(6): 594-602. [PubMed: 8257591]

31. Dahl M, Bauer AK, Arredouani M, Soininen R, Tryggvason K, Kleeberger SR, et al. Protection against inhaled oxidants through scavenging of oxidized lipids by macrophage receptors MARCO and SR-AI/II. J Clin Invest 2007;117(3):757-764. [PubMed: 17332894]

32. Otto-Knapp R, Jurgovsky K, Schierhorn K, Kunkel G. Antioxidative enzymes in human nasal mucosa after exposure to ozone. Possible role of GSTM1 deficiency. Inflamm Res 2003;52(2):5155. [PubMed: 12665121] 


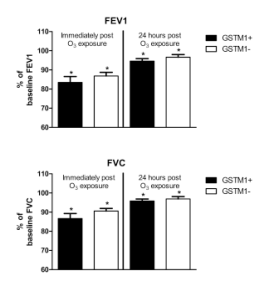

Figure 1. Effect of GSTM1 genotypes on lung function response to $\mathrm{O}_{3}$ FEV1 (top panel) and FVC (bottom panel) expressed as mean (SEM) percent of baseline value 4 and 24 hours after $\mathrm{O}_{3}$ exposure in GSTMI+ ( $\mathrm{N}=19$, closed bars) and GSTM1$(\mathrm{N}=16$, open bars ). 


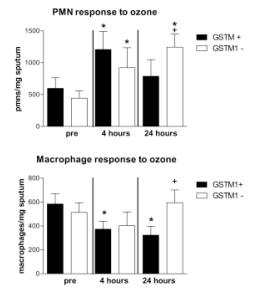

Figure 2. Effect of GSTM1 genotypes on PMN and macrophage numbers in sputum in response to $\mathrm{O}_{3}$

Mean (SEM) PMNs/mg sputum (top panel) and macrophages/mg sputum (bottom panel) pre (baseline), 4 and 24 hours post $\mathrm{O}_{3}$ exposure in GSTM1+ ( $\mathrm{N}=19$ closed bars) and GSTM1( $\mathrm{N}=16$ open bars) individuals. * $\mathrm{p}<0.05$ vs. baseline; ${ }^{+} \mathrm{p}<0.05$ GSTM1+ vs GSTM1- 


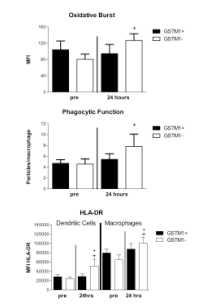

Figure 3. Effect of GSTM1 genotypes on cell function 24 hours after $\mathrm{O}_{3}$ exposure Mean (SEM) oxidative burst activity, MFI (top, macrophages, GSTM1+ =17, GSTM1=16), phagocytosis (middle, macrophages, GSTMI+=19, GSTM1-=15) and HLA-DR expression, MFI (bottom, GSTM1+ =9. GSTMI- =11) at 4 and 24 hours following ozone exposure in GSTM1+ and GSTM1- individuals. * $\mathrm{p}<0.05$ vs pre; ${ }^{+} \mathrm{p}<0.05$ for 24 hour response in GSTM1+ vs GSTM1- individuals 


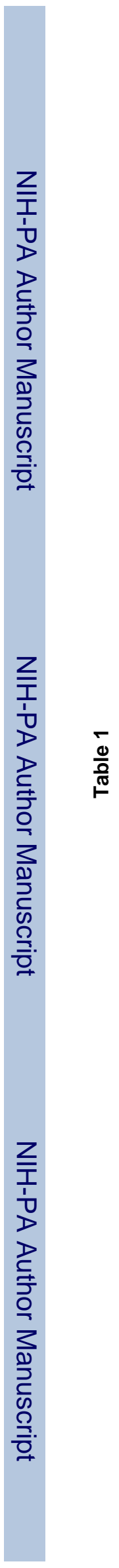

Alexis et al.

Page 14

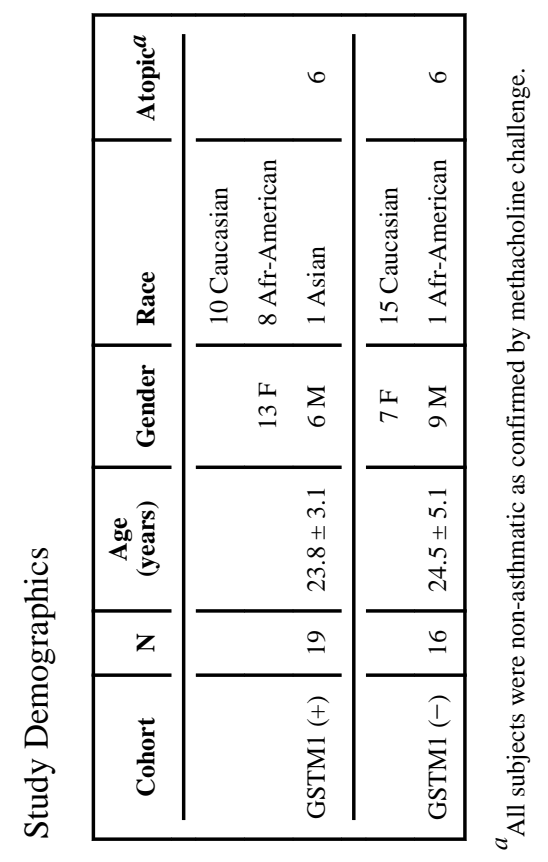

J Allergy Clin Immunol. Author manuscript; available in PMC 2011 February 14. 